DOI: $10.31933 /$ JEMSI

Received: 10 Oktober 2020, Revised: 18 Oktober 2020, Publish: 26 Oktober 2020

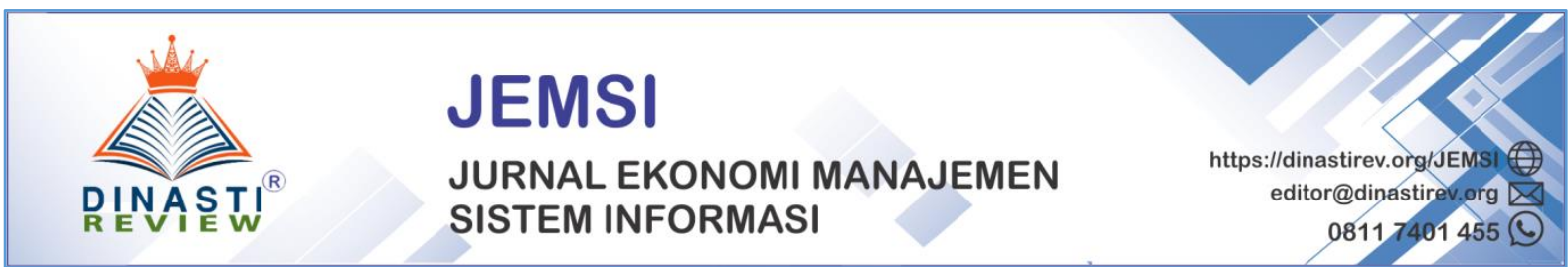

\title{
PENGARUH MOTIVASI ORGANISASI DAN KOMITMEN TERHADAP KINERJA KARYAWAN DENGAN ORGANIZATIONAL CITIZENHIP BEHAVIOR (OCB) SEBAGAI VARIABEL INTERVENING PADA KARYAWAN RUMAH SAKIT UMUM DAERAH (RSUD) Dr. MUHAMMAD ZEIN PAINAN
}

\author{
Rio Andhika Putra1, Dori Mittra Candana ${ }^{2}$ \\ ${ }^{1)}$ Universitas Putra Indonesia YPTK Padang, Indonesia, rioandhikaputra@ upiyptk.ac.id \\ ${ }^{2}$ Universitas Putra Indonesia YPTK Padang, Indonesia, dorimittra@upiyptk.ac.id
}

\section{Corresponding Author: First Author}

\begin{abstract}
Abstrak: Penelitian ini bertujuan untuk mengetahui seberapa besar pengaruhMotivasi dan Komitmen Organisasi secara bersama-sama (simultan) dan parsial terhadap Kinerja Karyawan dengan Organizational Citizenship Behavior (OCB) sebagai Variabel Intervening. Metode pengumpulan data melalui wawancara, kuesioner dan observasi. Metode analisis yang digunakan adalah uji validitas dan reabilitas,Uji Normalitas, Uji Multikolinieritas, Uji Heteroskedastisitas, Analisis Linier Berganda, Koefisien Determinasi, untuk Uji hipotesis digunakan Uji f dan Uji t danPath Analysisdengan Sampel berjumlah 85 responden. Dengan Hasil penelitian menunjukkan (a) Motivasi berpengaruh positif dan signifikan terhadap Organizational Citizenship Behavior (OCB) sebesar 4,817 dengan tingkat signifikan $(0,000<0,05)$. (b) Komitmen Organisasi berpengaruh positif dan signifikan terhadap Organizational Ctizenship Behavior (OCB)sebesar 3,214 dengan tingkat signifikan $(0,002<0,05)$. (c) Motivasi berpengaruh positif dan signifikan terhadap Kinerja Karyawan sebesar 8,219 dengan tingkat signifikan $(0.000<0.05)$. (d) Komitmen Organisasi berpengaruh negatif dan signifikan terhadap Kinerja Karyawan sebesar 2,372dengan tingkat signifikan $(0.020<0,05)$. (e) Organizational Citizenship Behavior (OCB) berpengaruh positif dan signifikan terhadap Kinerja Karyawan sebesar 5,191 dengan tingkat signifikan $(0,000<0,05)$. (f) Sumbangan Model 1 Hasil uji koefisien determinasi R Square sebesar 0,291 atau 29,1\%. Sedangkan sisanya adalah 70,9\% dipengaruhi oleh variabel lain di luar penelitian ini. (g) Sumbangan Model 2 Hasil uji koefisien determinasi $\mathrm{R}$ square sebesar 0,704 atau $70,4 \%$. Sedangkan sisanya adalah 29,6\% dipengaruhi oleh variabel lain di luar penelitian ini.
\end{abstract}

Kata Kunci: Motivasi Organisasi, Komitmen, Kinerja Karyawan Dan Organizational Citizenhip Behavior (OCB)

\section{PENDAHULUAN}

Penyelenggaraan Pemerintah Daerah pada hakekatnya tidak terlepas dari prinsipprinsip manajemen modern, dimana fungsi-fungsi manajemen harus berjalan secara simultan dan proporsional dalam kerangka mencapai tujuan organisasi. Pengawasan adalah salah satu fungsi organik menejemen yang harus ada dan dilaksanakan secara profesional sesuai standar dan norma yang berlaku dalam setiap penyelenggaraan pemerintah daerah, yaitu terhadap kewenangan setiap daerah otonom agar kewenangan tersebut tidak mengarah kepada 
kadaulatan dengan tindakan-tindakan menyimpang dari ketentuan yang berlaku.Rumah sakit merupakan bagian integral dari keseluruhan sistem pelayanan kesehatan yang melayani pasien dengan berbagai jenis pelayanan. Kesehatan mempunyai peranan besar dalam meningkatkan derajat hidup masyarakat, dalam pemberian pelayanan kesehatan yang optimal di rumah sakit diperlukan sumber daya yang berkualitas, dengan menggunakan sumber daya manusia yang berkualitas diharapkan rumah sakit dapat menghasilkan suatu output berupa produk jasa untuk meningkatkan pelayanan. Masalah tersebut haruslah disadari bahwa keberhasilan rumah sakit disebabkan oleh sumber daya manusia, sehingga sumber daya manusia dipandang sebagai asset rumah sakit, bahkan merupakan investasi rumah sakit apabila tenaga tersebut merupakan tenaga yang terampil.

Berikut merupakan laporan kehadiran karyawan RSUD Dr. Muhammad Zein Painan:

Tabel 1. Laporan Kehadiran

Caturwulan Pertama (Januari s/d April 2019)

\begin{tabular}{|l|c|c|c|c|c|c|}
\hline Bulan & $\begin{array}{c}\text { Jumlah } \\
\text { Karyawan }\end{array}$ & $\begin{array}{c}\text { Hadir } \\
\text { Tepat } \\
\text { Waktu }\end{array}$ & Terlambat & Sakit & Izin & Cuti \\
\hline Januari & 569 & 326 & 222 & 3 & 2 & 16 \\
\hline Februari & 569 & 289 & 250 & 7 & 2 & 21 \\
\hline Maret & 569 & 364 & 171 & 5 & 2 & 27 \\
\hline April & 569 & 319 & 211 & 5 & 3 & 31 \\
\hline
\end{tabular}

Sumber:RSUD Dr. Muhammad Zein Painan 2019

Berdasarkan data absensi di atas, dapat dilihat bahwa terjadi kenaikan tingkat keterlambatan pada bulan Februari. Namun pada bulan Maret jumlah keterlambatan kembali menurun dan kembali naik pada bulan April 2019. motivasi adalah suatu faktor yang mendorong seseorang untuk melakukan suatu aktivitas tertentu, oleh karena itu motivasi seringkali diartikan pula sebagai faktor pendorong perilaku seseorang.

komitmen organisasi merupakan loyalitas pegawai terhadap organisasi, yang tercermin dari keterlibatannya yang tinggi untuk mencapai tujuan organisasi. Loyalitas pegawai terlihat melalui kesediaan kemauan pegawai untuk selalu berusaha menjadi bagian dari organisasi, serta keinginannya yang kuat untuk bertahan dalam organisasi. komitmen organisasi dapat digunakan untuk memprediksi aktivitas profesional dan perilaku kerja karena komitmen organisasi mencerminkan sikap positif individu pada organisasi. Sikap ini memotivasi seseorang untuk berperilaku positif, untuk menjadi disiplin dalam bekerja, untuk mematuhi aturan dan kebijakan organisasi, untuk menjaga hubungan baik dengan rekan kerja, dan meningkatkan tingkat pencapaian seseorang. Dengan cara ini, pengetahuan dan pemahaman tentang komitmen organisasi dapat digunakan sebagai dasar untuk memprediksi perilaku kerja individu.

Serta komitmen organisasi yang tinggi akan cenderung menampilkan Organizational Citizenship Behavior (OCB) yang tinggi pula dari pegawai, dengan sikap bersedia menyelesaikan pekerjaannya hingga tuntas dan memiliki serta menjalankan prinsip-prinsip etika dalam melakukan pekerjaannya, cenderung tidak terpengaruh jika rekan kerjanya mendapatkan hak istimewa dari atasan yang tidak didapatakan olehnya, tetap antusias dan sungguh-sungguh dalam melakukan pekerjaan sukarela mengambil tanggung jawab ekstra dalam pekerjaan. 


\section{KAJIAN PUSTAKA \\ Kinerja Karyawan}

Menurut Kasmir (2016:182) kinerja adalah hasil kerja dan perilaku kerja yang dicapai dalam menyelesaikan tugas-tugas dan tanggung jawab yang diberikan dalam suatu periode tertentu. Menurut Suhardi (2015) kinerja adalah hasil kerja yang secara kualitas dan kuantitas yang dicapai oleh seorang pegawai dalam melaksanakan tugasnya sesuai dengan tanggung jawab yang diberikan kepadanya. Menurut Miner dalam Putri Y.A (2018:195) untuk mencapai atau menilai kinerja, ada dimensi yang menjadi tolak ukur, yaitu:

1. Kualitas, yaitu: tingkat kesalahan, kerusakan, kecermatan.

2. Kuantitas, yaitu: jumlah pekerjaan yang dihasilkan.

3. Penggunaan waktu dalam kerja, yaitu: ketidakhadiran, keterlambatan, waktu kerja efektif/kerja jam hilang.

4. Kerjasama dengan orang lain dalam bekerja.

\section{Organizational Citizenship Behavior (OCB)}

Organizational Citizenship Behavior (OCB) dapat didefenisikan sebagai perilaku atau individu bebas, yang tidak berkaitan secara langsung dengan sistem reward dan mampu meningkatkan fungsi efektif organisasi Organ dalam Deny (2017:3). Menurut Djati dalam Titisari (2014:6) OCB merupakan perilaku karyawan baik terhadap rekan kerja ataupun perusahaan, yang mana perilaku tersebut melebihi dari perilaku standar yang ditetapkan perusahaan dan memberikan manfaat positif bagi perusahaan. Organizational Citizenship Behavior (OCB) dalam penelitian ini diukur dengan menggunakan indikator dari Organ et al, dalam Titisari (2014:7) yaitu:

1. Altruism (menolong rekan kerja)

2. Conscientiousness (patuh terhadap peraturan dan melebihi harapan perusahaan)

3. Sportmanship (toleransi terhadap hal yang kurang ideal)

4. Courtesy (menjaga hubungan baik dengan rekan kerja)

5. Civic Virtue (mengikuti perkembangan organisasi)

\section{Motivasi}

Menurut Pamelo \& Aloko (2015) motivasi adalah knuci dari organisasi yang sukses untuk menjaga kelangsungan pekerjaan dalam organisasi dengan cara dan bantuan yang kuat untuk bertahan hidup. Motivasi adalah memberikan bimbingan yang tepat atau arahan, sumber daya dan imbalan agar mereka terinspirasi dan tertarik untuk bekerja dengan cara yang diinginkan. Motivasi adalah suatu proses dimana kebutuhan-kebutuhan mendorong seseorang untuk melakukan serangkaian kegiatan yang mengarah tercapainya tujuan tertentu Chukwuma \& Obiefuna (2014). Adapaun indikator dari motivasi menurut Maslow dan Hasibuan (2013:154):

1) Kebutuhan Fisiologis (Physiological Needs)

2) Kebutuhan Keselamatan dan Keamanan (Safety and Security Needs)

3) Kebutuhan Sosial (Affiliation or Acceptance Needs)

4) Kebutuhan akan Penghargaan (Asteem or Satus Needs)

5) Aktualisasi Diri (Sef Actualization) 


\section{Komitmen Organisasi}

Menurut Priansa (2016:234) komitmen organisasional adalah loyalitas pegawai terhadap organisasi, yang mencerminkan dari keterlibatannya yang tinggi untuk mencapai tujuan organisasi. Komitmen organisasional didefenisikan sebagai suatu sikap yang merefleksikan perasaaan suka atau tidak suka dari karyawan terhadap organisasi. Sedangkan menurut Dessler dalam Priansa (2016:234) menyatakan bahwa komitmen organisasi merupakan identifikasi pegawai terhadap persetujuan untuk mencapai misi unit atau misi organisasi. Menurut Priansa (2016:239-242) mengemukakan tiga dimensi komitmen organisasi, yaitu:

1. Komitmen Afektif (affective commitment)

2. Komitmen Normatif (normative commitment)

3. Komitmen Berkelanjutan (continuance commitment)

\section{Kerangka Fikir}

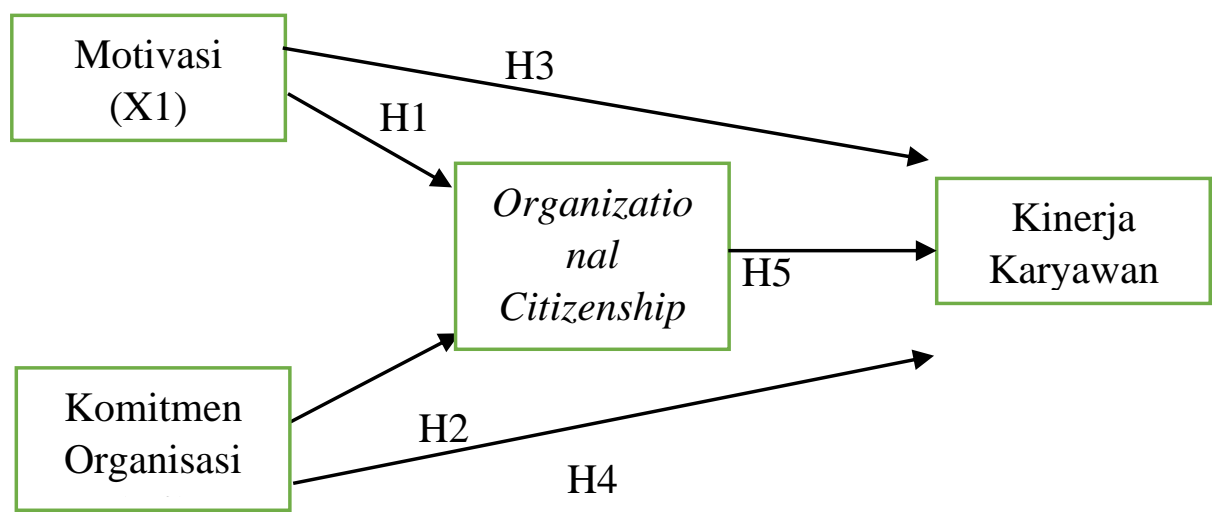

\section{Gambar 1. Kerangka Penelitian}

\section{METODE PENELITIAN}

Penelitian ini menggunakan metode kualitatif dimana dalam pengolahan data menggunakan program SPSS versi 21dengan sampel sebanyak 85. Metode analisis yang digunakan adalah uji validitas dan reabilitas,Uji Normalitas, Uji Multikolinieritas, Uji Heteroskedastisitas, Analisis Linier Berganda, Koefisien Determinasi, untuk Uji hipotesis digunakan Uji f dan Uji t, Path Analysis

\section{HASIL DAN PEMBAHASAN}

\section{Hasil Uji Korelasi}

Tabel 2. Hasil Analisis Korelasi Variabel Variabel Motivasi(X1), Komitmen Organisasi (X2), dan Organization Citizenship Behavior(Z)

\begin{tabular}{|l|c|c|}
\hline \multicolumn{1}{|c|}{ Variabel } & Kinerja Karyawan(Y) & Tingkat Signifikan \\
\hline Motivasi $\left(\mathbf{X}_{\mathbf{1}}\right)$ & $0,732 * *$ & 0,000 \\
\hline Komitmen Organisasi $\left(\mathbf{X}_{\mathbf{2}}\right)$ & $0,268 *$ & 0,013 \\
\hline $\begin{array}{l}\text { Organization Citizenship } \\
\text { Behavior }(\mathbf{Z})\end{array}$ & $0,672 * *$ & 0,000 \\
\hline
\end{tabular}

Sumber : data primer (diolah)

Interprestasi dari hasil analisis tabel 2 diatas dapat dilihat korelasi antara masingmasing variabel, yaitu : 
1. Korelasi anatara variable Motivasi dengan Kinerja Karyawan adalah 0,732hubungan kedua variable sedang, dengan signifikan 0,000

2. Korelasi anatara variabel Komitmen Organisasi dengan Kinerja Karyawan adalah 0,268 hubungan kedua variable lemah, dengan signifikan0,013.

3. Korelasi anatara variabel Organization Citizenship Behaviordengan Kinerja Karyawan adalah 0,672 hubungan kedua variable sedang, dengan signifikan 0,000.

\section{Hasil Uji Model Path}

\section{Model I}

Tabel 3.

Hasil Regresi Jalur Variabel Motivasi $\left(X_{1}\right)$, Komitmen Organisasi $\left(X_{2}\right)$, terhadap Organization Citizenship Behavior $(Z)$

Coefficients $^{\mathrm{a}}$

\begin{tabular}{|c|c|c|c|c|c|c|}
\hline \multirow{2}{*}{\multicolumn{2}{|c|}{ Model }} & \multicolumn{2}{|c|}{$\begin{array}{c}\text { Unstandardized } \\
\text { Coefficients }\end{array}$} & $\begin{array}{l}\text { Standardized } \\
\text { Coefficients }\end{array}$ & \multirow[t]{2}{*}{$\mathrm{t}$} & \multirow[t]{2}{*}{ Sig. } \\
\hline & & B & Std. Error & Beta & & \\
\hline \multirow{3}{*}{1} & (Constant) & 9,234 & 5,895 & & 1,566 & ,121 \\
\hline & motivasi (X1) &, 539 &, 112 & ,448 & 4,817 &, 000 \\
\hline & komitmen organisasi (X2) & ,310 & ,096 & ,299 & 3,214 &, 002 \\
\hline
\end{tabular}

b. Dependent Variable: Organizational Citizenship Behavior (OCB) (Z)

Berdasarkan tabel diatas maka dapat dilihat persamaan regresinya yaitu :

$$
\mathrm{Z}=\mathbf{0 , 4 4 8 X _ { 1 } + 0 , 2 9 9 X _ { 2 }}
$$

1. Motivasimempunyai pengaruh yang positif dan signifikan terhadap Organizational Citizenship Behavior (OCB)

$\mathrm{H}_{\mathrm{O}}=$ Tidak ada pengaruh Motivasi dengan Organization Citizenship Behavior

$\mathrm{H}_{\mathrm{a}}=$ Ada pengaruh Motivasi dengan Organization Citizenship Behavior

Dari tabel 4.18 diatas di ketahui variabel Motivasi t hitung > t tabel $(4,817>1,663)$ dengan tingkat siginifikan $(0,000<0,05)$, artinya secara parsial ada pengaruh yang positif signifikan antara Motivasi dengan Organization Citizenship Behavior. Dengan demikian Ho ditolak dan $\mathrm{H} 1$ diterima.

2. Komitmen Organisasi mempunyai pengaruh yang positif dan signifikan terhadapOrganizationsl Citizenship Behavior (OCB)

$\mathrm{H}_{\mathrm{O}}=$ Tidak ada pengaruh Komitmen Organisasi terhadap Organization Citizenship Behavior

$\mathrm{H}_{\mathrm{a}}=$ Ada pengaruh Komitmen Organisasi terhadap Organization Citizenship Behavior

Dari tabel 4.18 diatas diketahui variabel Komitmen Organisasit hitung $>\mathrm{t}$ tabel $(3,214>1,663)$ dengan tingkat signifikan $(0,002<0,05)$, artinya secara persial ada pengaruh yang positif signifikan antara Komitmen Organisasi terhadap Organization Citizenship Behavior. Ho ditolakdan $\mathrm{H} 2$ diterima. 
Dengan demikian diperoleh diagram jalur model struktur I sebagai berikut :

\section{Diagram Analisis Jalur Model I}

e1 0,842



\section{Model II}

Tabel 4.

Hasil Regresi Jalur Variabel Motivasi $\left(\mathbf{X}_{1}\right)$, Komitmen Organisasi $\left(\mathbf{X}_{2}\right)$, Organization Citizenship Behavior $(Z)$ terhadap Kinerja Karyawan (Y)

Coefficients $^{\mathrm{a}}$

\begin{tabular}{|c|c|c|c|c|c|c|}
\hline \multirow{2}{*}{\multicolumn{2}{|c|}{ Model }} & \multicolumn{2}{|c|}{$\begin{array}{c}\text { Unstandardized } \\
\text { Coefficients }\end{array}$} & \multirow{2}{*}{$\begin{array}{c}\begin{array}{c}\text { Standardized } \\
\text { Coefficients }\end{array} \\
\text { Beta }\end{array}$} & \multirow[t]{2}{*}{$\mathrm{t}$} & \multirow[t]{2}{*}{ Sig. } \\
\hline & & B & Std. Error & & & \\
\hline \multirow{4}{*}{1} & (Constant) & 9,715 & 2,585 & & 3,758 &, 000 \\
\hline & motivasi (X1) &, 450 &, 055 & ,563 & 8,219 &, 000 \\
\hline & komitmen organisasi (X2) & , 105 & 044 & , 152 & 2,372 &, 020 \\
\hline & OCB $(\mathrm{Z})$ & ,248 & ,048 & ,373 & 5,191 &, 000 \\
\hline
\end{tabular}

a. Dependent Variable :kinerja Karyawan $(Y)$

Berdasarkan tabel diatas maka dapat dilihat persamaan regresinya yaitu :

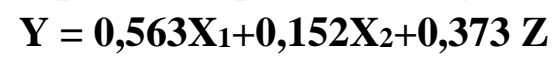

3. Motivasimempunyai pengaruh yang positif sigifikanterhadap Kinerja Karyawan

$\mathrm{H}_{\mathrm{O}}=$ Tidak ada pengaruh Motivasi terhadap Kinerja Karyawan

$\mathrm{H}_{\mathrm{a}}=$ Ada pengaruh Motivasi terhadap Kinerja Karyawan

Dari tabel 4. diatas di ketahui variabel Motivasit hitung $>t$ tabel $(8,219>1,663)$ dengan tingkat siginifikan $(0,000<0,05)$, artinya secara parsial ada pengaruh positif yang signifikan antara Motivasi dengan Kinerja Karyawan. Dengan demikian Ho ditolak dan H3 diterima.

4. Komitmen Organisasi mempunyai pengaruh yang positif dan signifikan terhadap Kinerja Karyawan

$\mathrm{H}_{\mathrm{O}}=$ Tidakada pengaruh Komitmen Organisasi terhadap Kinerja Karyawan

$\mathrm{H}_{\mathrm{a}}=$ Ada pengaruh Komitmen Organisasi terhadap Kinerja Karyawan

Dari tabel diatas 4.19 di ketahui variabel Komitmen Organisasit hitung $<\mathrm{t}$ tabel $(2,372<1,663)$ dengan tingkat siginifikan $(0,020<0,05)$, artinya secara parsial ada 
pengaruh positif yangsignifikan antara Komitmen Organisasidengan Kinerja Karyawan. Dengan demikian Ho ditolak dan H4 diterima.

5. Organizational Citizenship Behavior (OCB) mempunyai pengaruh yang positif dan signifikan terhadap Kinerja Karyawan

$\mathrm{H}_{\mathrm{O}}=$ Tidak ada pengaruh Organization Citizenship Behavior terhadap Kinerja Karyawan $\mathrm{H}_{\mathrm{a}}=$ Ada pengaruh Organization Citizenship Behavior terhadap Kinerja Karyawan

Dari tabel 4.19 diatas diketahui variabel Organization Citizenship Behavior t hitung $>\mathrm{t}$ tabel $(5,191>1,663)$ dengan tingkat signifikan $(0,000<0,05)$, artinya secara persial ada pengaruh yang positif dansignifikan antaraOrganization Citizenship Behavior terhadap Kinerja Karyawan. Ho ditolakdan H5diterima.

Dengan demikian diperoleh diagram jalur model struktur II sebagai berikut :

\section{Diagram Analisis Jalur Model II}

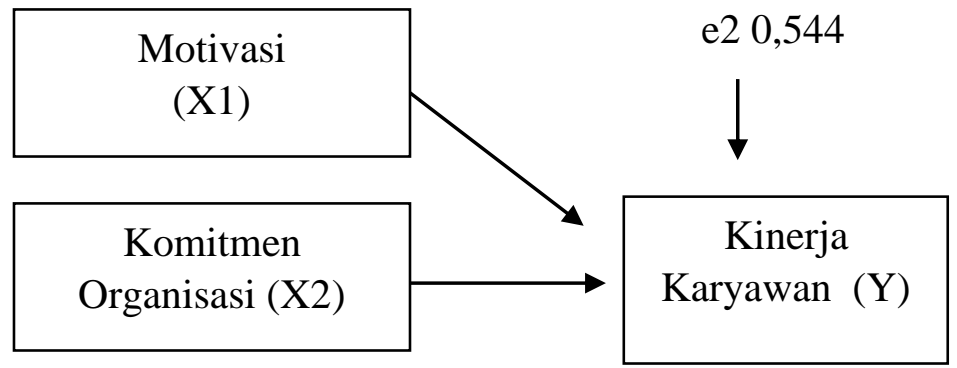

0,299

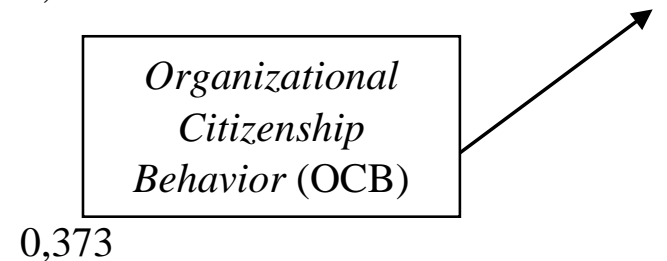

Analisis Koefisien Determinasi $\left(\mathbf{R}^{2}\right)$

Model I

Tabel 5.

Hasil Koefisien Determinasi Variabel Motivasi $\left(X_{1}\right)$, Komitmen Organisasi $\left(X_{2}\right)$, terhadap Organization Citizenship Behavior (Z) Model Summary

\begin{tabular}{|l|r|r|r|r|}
\hline Model & \multicolumn{1}{|c|}{$\mathrm{R}$} & R Square & $\begin{array}{c}\text { Adjusted R } \\
\text { Square }\end{array}$ & Std. Error of the Estimate \\
\hline 1 &, $540^{\mathrm{a}}$ &, 291 &, 274 & \\
\hline
\end{tabular}

Sumber :SPSS 21.0 dan data primer yang diolah

Berdasarkan tabel di atas diperoleh angkaR square pada model 1 sumbangan sebesar 0,291 atau29,1\%, hal ini menunjukkan bahwa persentase sumbangan Model I Motivasi( $\left.\mathrm{X}_{1}\right)$, Komitmen Organisasi $\left(\mathrm{X}_{2}\right)$ terhadap OCB (Z) sebesar 29,1\%, sedangkan sisanya sebesar $70,9 \%$ dipengaruhi variabel lain yang tidak diteliti. 


\section{Model II}

Tabel 6.

Hasil Koefisien Determinasi Variabel Motivasi $\left(\mathbf{X}_{1}\right)$, Komitmen Organisasi $\left(\mathbf{X}_{2}\right)$, Organization Citizenship Behavior $(Z)$ terhadap Kinerja Karyawan (Y)

Model Summary

\begin{tabular}{|l|r|r|c|c|}
\hline Model & \multicolumn{1}{|c|}{$\mathrm{R}$} & $\mathrm{R}$ Square & $\begin{array}{c}\text { Adjusted R } \\
\text { Square }\end{array}$ & Std. Error of the Estimate \\
\hline 1 &, $839^{\mathrm{a}}$ &, 704 &, 693 & 3,46805 \\
\hline
\end{tabular}

Sumber :SPSS 21.0 dan data primer yang diolah

Berdasarkan tabel di atas diperoleh angkaR square pada model 1I sumbangan sebesar 0,704 atau 70,4\%, hal ini menunjukkan bahwa persentase sumbangan Model II Motivasi $\left(\mathrm{X}_{1}\right)$, Komitmen Organisasi $\left(\mathrm{X}_{2}\right)$ dan Organization Citizenship Behavior (Z) terhadap variabel dependen Kinerja Karyawan (Y) sebesar 70,4\%, sedangkan sisanya sebesar $29.6 \%$ dipengaruhi variabel lain yang tidak diteliti.

Uji Hipotesis Secara Simultan (Uji F)

\section{Model I}

Tabel 7. Pengujian Hipotesis Secara Bersama-Sama (Uji F)

ANOVA $^{\mathrm{a}}$

\begin{tabular}{|rl|r|r|r|r|r|}
\hline \multicolumn{1}{|l|}{ Model } & Sum of Squares & \multicolumn{1}{|c|}{ Df } & Mean Square & F & \multicolumn{1}{c|}{ Sig. } \\
\hline \multirow{3}{*}{1} & Regression & 2173,135 & 2 & 1086,567 & 16,865 &, $000^{\mathrm{b}}$ \\
& Residual & 5282,912 & 82 & 64,426 & & \\
& Total & 7456,047 & 84 & & & \\
\hline
\end{tabular}

Sumber : data primer (diolah)

Dari tabel 7 di atas dapat dilihat pengujian ini dilakukan dengan cara membandingkan nilai $\mathrm{F}_{\text {hitung }}$ dengan $\mathrm{F}_{\text {tabel }}$ karena nilai $\mathrm{F}_{\text {hitung }}$ lebih besar dari nilai $\mathrm{F}_{\text {tabel }}(16,865>2,72)$ dengan tingkat signifikan 0,000 lebih kecil dari 0,05. Maka diperoleh $\mathrm{H}_{\mathrm{o}}$ ditolak dan $\mathrm{H}_{\mathrm{a}}$ diterima, yang berarti hal ini dilakukan secara bersama-sama antaraMotivasidanKomitmen Organisasiberpengaruh positif dan signifikan terhadap Organization Citizenship Behavior.

\section{Model II}

Tabel 8. Pengujian Hipotesis Secara Bersama-Sama (Uji F)

ANOVA $^{\mathrm{a}}$

\begin{tabular}{|rl|r|r|r|r|c|}
\hline Model & & Sum of Squares & \multicolumn{1}{|c|}{ Df } & Mean Square & F & Sig. \\
\hline \multirow{2}{*}{1} & Regression & 2313,029 & 3 & 771,010 & 64,105 &, $000^{\mathrm{b}}$ \\
& Residual & 974,218 & 81 & 12,027 & & \\
& Total & 3287,247 & 84 & & & \\
\hline
\end{tabular}

Sumber : data primer (diolah)

Dari tabel 8 di atas dapat dilihat pengujian ini dilakukan dengan cara membandingkan

nilai $\mathrm{F}_{\text {hitung }}$ dengan $\mathrm{F}_{\text {tabel }}$ karena nilai $\mathrm{F}_{\text {hitung }}$ lebih besar dari nilai $\mathrm{F}_{\text {tabel }}(64,105>2,72)$ dengan tingkat signifikan 0,000 lebih kecil dari 0,05. Maka diperoleh $\mathrm{H}_{\mathrm{o}}$ ditolak dan $\mathrm{H}_{\mathrm{a}}$ diterima, yang berarti hal ini dilakukan secara bersama-sama antara Motivasi, Komitmen Organisasi dan Organization Citizenship Behavior berpengaruh positif dan signifikan terhadap Kinerja Karyawan. 
Berdasarkan penelitian yang peneliti lakukan melalui analisis statistik dari kuesioner yang disebarkan maka dapat ditarik kesimpulan sebagai berikut:

\section{KESIMPULAN DAN SARAN}

Berdasarkan penelitian yang peneliti lakukan melalui analisis statistik dari kuesioner yang disebarkan maka dapat ditarik kesimpulan sebagai berikut:

1. Motivasi mempunyai pengaruh yang positif dan signifikan terhadap Organizational Citizenship Behavior (OCB) Pada RSUD Dr. Muhammad Zein Painan.

2. Komitmen Organisasi mempunyai pengaruh yang positif dan signifikan terhadap Organizational Citizenship Behavior (OCB)Pada RSUD Dr. Muhammad Zein Painan.

3. Motivasi mempunyai pengaruh yang positif dan signifikan terhadap Kinerja RSUD Dr. Muhammad Zein Painan.

4. Komitmen Organisasi mempunyai pengaruh yang positif dan signifikan terhadap Kinerja RSUD Dr. Muhammad Zein Painan.

5. Organizational Citizenship Behavior (OCB) mempunyai pengaruh yang positif dan signifikan terhadap Kinerja Pada RSUD Dr. Muhammad Zein Painan.

6. Organizational Citizenship Behavior (OCB) tidak memediasi hubungan pengaruh Motivasi terhadap Kinerja Karyawan.

7. Organizational Citizenship Behavior (OCB) tidak memediasi hubungan pengaruh Komitmen Organisasi terhadap Kinerja Karyawan.

\section{DAFTAR RUJUKAN}

Agus, S., Abdul, S., \& Ika, H. (2019). Jurnal Ilmiah Mahasiswa Manajemen dan Bisnis.2(1), 1-12. Lintong, D. C., Ekonomi, F., \& Manajemen, J. (2018).Pengaruh Kepuasan Kerja Dan Komitmen Organisasi Terhadap Organizational Citizenship Behavior (Ocb) Pegawai Pada Kantor Sekretariat Daerah Kabupaten Minahasa Tenggara.Jurnal EMBA: Jurnal Riset Ekonomi, Manajemen, Bisnis Dan Akuntansi, 6(4), 3138-3147.

Nisa, D. K., Santoso, B., \& Azhad, M. N. (2018). Pengaruh Budaya Organisasi dan Organizational Citizenship Behavior (OCB) terhadap Kinerja Pegawai Rumah Sakit Tk. III Baladhika Husada Jember.International Journal of Social Science and Business, 2(3), 108. https://doi.org/10.23887/ijssb.v2i3.16219

Kepemimpinan, P., Organisasi, D. A. N. I., Kinerja, T., Di, K., Mina, W., Bagus, I. G., \& Satrya, H. (2019).PEGUYANGAN DENPASAR I Kadek Adnyana Dwi Putra 1 Fakultas Ekonomi dan Bisnis Universitas Udayana ( Unud ), Bali, Indonesia 8(5), 2918-2943.

Shofwani, S. A., \& Hariyadi, A. (2019). Pengaruh Kompensasi, Motivasi Dan Disiplin Kerja Terhadap Kinerja Karyawan Universitas Muria Kudus. Jurnal Stie Semarang, 11(1), 52-65. https://doi.org/10.33747/stiesmg.v11i1.338

Ekonomi, F., \& Udayana, U. (2018).DAN BUDAYA ORGANISASIONAL TERHADAP ORGANIZATIONAL CITIZENSHIP BEHAVIOUR KARYAWAN Kadek Andi Darmawan I Gst .Bgs . Honor Satrya 7(5), 2508-2537.

Kepuasan, D., Terhadap, K., Karyawan, K., Kurniawan, R. A., Qomariah, N., \& Winahyu, P. (2019).Dampak Organizationlal Citizenship Behavior, Motivasi. 4(2), 148-160.

Adi, I. P., Putra, K., \& Sudibya, I. G. A. (2018).BEHAVIOR Fakultas Ekonomi dan Bisnis Universitas Udayana ( Unud ), Bali, Indonesia 7(8), 4447-4474.

Suputra, I. D. N. S. A., \& Sriathi, A. A. A. (2018). Pengaruh Motivasi Kerja Dan Kepuasan Kerja Terhadap Komitmen Organisasional. E-Jurnal Manajemen Universitas Udayana, 7(9), 4628. https://doi.org/10.24843/ejmunud.2018.v07.i09.p01

Susan, E. (2019). MANAJEMEN SUMBER DAYA MANUSIA Eri Susan 1.Jurnal Manajemen Pendidikan, (2), 952-962. 
Rachman, A. K. (2017). EVALUASI KOMITMEN ORGANISASI PADA ANGGOTA DEMADI. 2.

Dadang Haryanto, W. S. F. (2017). Jurnal Manajemen Jurnal Manajemen. 8(2), 137-144.

Awanti, H., Fathoni, A., \& Malik, D. (2018).Mahasiswa Jurusan Manajemen Fakultas Ekonomika dan Bisnis Universitas Pandanaran Semarang Dosen Jurusan Manajemen Fakultas Ekonomika dan Bisnis Universitas Pandanaran.

Awanti, H., Fathoni, A., \& Malik, D. (2018).Mahasiswa Jurusan Manajemen Fakultas Ekonomika dan Bisnis Universitas Pandanaran Semarang Dosen Jurusan Manajemen Fakultas Ekonomika dan Bisnis Universitas Pandanaran. (6).

Ratnaningrum, D., Suddin, A., Studi, P., Fakultas, M., Universitas, E., \& Riyadi, S. (2017). PENGARUH KOMITMEN ORGANISASI DAN KOMPENSASI TERHADAP KINERJA KARYAWAN DENGAN ORGANIZATIONAL CITIZENSHIP BEHAVIOR SEBAGAI VARIABEL INTERVENING (Survei Pada Karyawan Bagian Produksi PT Ventura Cahaya Mitra Sukoharjo).17(2), 330-343.

Negara, A. K., \& Febrianti, R. W. (2019).Pengaruh motivasi pelayanan publik, perceived organizational support dan organizational citizenship behavior terhadap kinerja organisasi sektor publik di kota tangerang. 3(2), 53-64. Retrieved from http://jurnal.umt.ac.id/index.php/dmj/article/view/1962/1192

Dewi, I. S., Setiawan, H. I., Ekonomi, F., Galuh, U., \& Interersonal, K. (2019).PENGARUH KARAKTERISTIK PEKERJAAN DAN KOMUNIKAS INTERPERSONAL TERHADAP KOMITMEN ORGANISASI (Suatu Studi pada Karyawan Toserba Gunasalma Kawali). 1, 1-13.

Ramadianty, D., \& Aini, E. K. (2018). PENGARUH MOTIVASI TERHADAP ORGANIZATIONAL CITIZENSHIP BEHAVIOR ( OCB ) KARYAWAN GEN-X DAN MILLENIALS ( Studi Pada Karyawan PT Temprina Media Grafika Surabaya ). Jurnal Administrasi Bisnis (JAB), 60(2), 19.

Setiawati, F., \& Mulawarman, U. (n.d.).Pengaruh beban kerja dan karakteristik individu terhadap kinerja karyawan pada pt. maybank indonesia tbk cabang pusat samarinda.

Jaya, R. (2018). Pengaruh Komitmen Organisasi Terhadap Organisazional Citizenship Behavior (Ocb) Pegawai Pada Bptpm Kota Pekanbaru.Jurnal EL-RIYASAH, 8(1), 10. https://doi.org/10.24014/jel.v8i1.4404

Can, A., \& Yasri. (2016). Pengaruh Motivasi Kerja, Kepuasan Kerja dan Komitmen Organisasi Terhadap Kinerja Karyawan pada Bank Nagari.Jurnal Riset Manajemen Bisnis Dan Publik, 4(1), 1-26.

Tipe, P., Komitmen, K., Ocb, B., Kinerja, D. A. N., Di, P., Sularso, R. A., ... Jember, U. (2017). Motivasi Terhadap Organization Citizenship.11(3), 297-310.

Pradita, T. R., Wardhana, A., Telkom, U., Demokratis, G. K., \& Karyawan, K. (2018).PENGARUH GAYA KEPEMIMPINAN DEOKRATIS TERHADAP KINERJA KARYAWAN PT . ASTRA INTERNATIONAL Tbk - TOYOTA SALES OPERATION ( AUTO2OOO ) CABANG SOEKARNO HATTA BANDUNG EFFECT OF DEMOCRATIC LEADERSHIP STYLE ON EMPLOYEE PERFORMANCE ON SALES OPERATION IN PT ASTRA IN. 5(2), 2627-2633.

Maulani, V. H., \& Dewi, R. S. (n.d.).TERHADAP KINERJA KARYAWAN MELALUI ORGANIZATIONAL CITIZENSHIP BEHAVIOR ( OCB ) SEBAGAI VARIABEL INTERVENING ( Studi Kasus pada Karyawan PT Masscom Graphy Semarang ) Hima, M., Bisnis, A., \& Komunikasi, F. (2019). PENGARUH BUDAYA ORGANISASI TERHADAP KINERJA PENGURUS HIMPUNAN BISNIS UNIVERSITAS TELKOM THE EFFECT OF ORGANIZATIONAL CULTURE ON PERFORMANCE OF STUDENT COLLECTORS ( HIMA ) BUSINESS ADMINISTRATION FACULTY OF TELKOM UNIVERSITY COMMUNICATION AND BUSINESS. 6(1), 1028-1034.

Komang, N., \& Wahyudi, S. (2016). PENGARUH KEPUASAN KERJA DAN KOMITMEN ORGANISASIONAL PADA KINERJA KARYAWAN DI NATYA HOTEL , Fakultas Ekonomi dan Bisnis Universitas Udayana ( Unud ), Bali, Indonesia 5(2), 870-897. 